\title{
Forest Research Priorities in Canada, 1991
}

\author{
An Overview for the Canadian Council of Forest Ministers \\ Prepared by the Forestry Research Advisory Council of Canada \\ in Cooperation with the Forestry Research Advisory Committees in \\ the Provinces and Territories \\ Ottawa, August 1991
}

\section{Summary}

This third annual overview of forest research priorities across Canada has been prepared by the Forestry Research Advisory Council of Canada for the Canadian Council of Forest Ministers. It is based on input from the provincial and territorial forest research bodies, who were asked to give their top five priorities for forest research.

The priorities so identified were assembled and assigned scores, ranging from five points for a jurisdiction's top priority down to one point for its lowest. The result is a list of 12 forest research topics presented here in descending order of priority.

- Environmental effects of forest management.

- Pest and weed management and alternatives to chemicals.

- Decision support for management, silviculture and land use.

- Ecological knowledge for intensive forest management.

- Integrated resource management systems.

- Site-productivity classification systems.

- Growth and yield data for managed and unmanaged stands.

- Silvicultural and harvesting methods and cost reduction.

- Forest fire management and control.

- Tree improvement and genetics.

- Increasing forest productivity.

- Wood processing and value-added products.

The importance of modern information-handling systems, artificial intelligence, and biotechnology in conducting research was frequently mentioned by respondents, but because these are usually considered research tools rather than research topics, they have not been rated.

Comparing this year's priorities with those of previous years might raise some concerns that priorities are changing faster than research programs can adjust. However, the current priorities are not new. Although wording and grouping may differ, they all were covered in the Research Priorities Overview for 1990, where most were identified as priorities by a majority of respondents. Identifying only the top five priorities in each jurisdiction has focused attention on the major problems and research needs and made it possible to simplify the categorization of the topics.

Few of the 12 topics are considered adequately funded in any region and research on the environmental effects of forest management appears to be undersupported in all regions. All responses stress the importance of the federal-provincial forestry agreements in supporting research. Suggestions for improving support include placing more emphasis on cooperative programs such as interprovincial cooperation and joint approaches to funding agencies; the gathering of special pools of funds from industry and governments and their joint administration to support project proposals; and the reallocation of funds from work of lesser importance.
Thirteen issues that may affect research priorities were identified as follows:

- Public concern about forestry, the environment and sustainable development.

- International opinion about Canadian forestry practices.

- Globalization of trade and increased competition.

- Economics of viable secondary forest-products industries.

- Increasing requirements for information at all levels.

- Shrinking forest land base for sustained timber harvest.

- Forest modeling and sustainable harvests.

- Information on the socioeconomic importance of the forests.

- Monitoring the managed forest to ensure predicted yields.

- Managing the boreal mixed-wood resource.

- Forestry on Indian lands.

- Small-scale forestry on farms and for shelterbelts.

- Properties of wood from managed stands.

A few of these topics have appeared in previous lists of research priorities in this series of overviews, for example, "Small-scale forestry on farms and for shelterbelts," "Forestry on Indian lands" and "Properties of wood from managed stands." They do not appear in the 1991 priority listing because they are not in the top five priorities in any jurisdiction. However, these and other concerns, many of which are local, must figure in the final mix of research projects undertaken by any agency.

Forest research in Canada is considered pertinent to needs, but more effort to improve local applications of research results and increased funding for most regions are required.

\section{Introduction}

This is the third annual overview of research priorities compiled by the Forestry Research Advisory Council of Canada (FRACC). In 1987 FRACC proposed that each province and territory establish a research advisory body and that an annual Canada-wide survey of research priorities and issues be prepared for the Canadian Council of Forest Ministers (CCFM) drawing on the priorities identified in each jurisdiction. The 1989 and 1990 reports were presented to the ministers at their fall meetings and subsequently published in The Forestry Chronicle in December 1989 and February 1991. This third report is based on material provided by the provincial advisory groups in early 1991 .

The process for assembling the data has evolved toward a simpler and more concise reporting by each participant. This year each advisory group prepared a short document responding to the following requests:

- Name the five top forest research priorities for work needed to ensure a sustainable flow of all forest benefits.

- Of the five topics named, identify those that are adequately funded and supported. 
- Identify those that are not adequately funded and supported.

- If possible, suggest how to fund work that is not adequately funded.

- Describe emerging issues that are likely to affect future forest research priorities.

- Comment on the adequacy of forest research in your area.

This documentation was sent to the Executive Secretary of FRACC, who prepared a draft for review at a joint meeting of FRACC and the provincial and territorial representatives on May 8, 1991, at the Petawawa National Forestry Institute. It was then revised for presentation to the CCFM.

\section{Research Priorities}

The information on research priorities was tabulated by origin and subject. The result is a list of 12 research topics identified by one or more advisory groups as being among their top five priorities. Each topic was assigned a score, ranging from five for the highest to one for the lowest priority in a jurisdiction. Table 1 presents the topics in descending order of priority as determined by this scoring method.

Nova Scotia and Ontario have fewer than five topics rated in the table because some were combined under one heading and the scores adjusted accordingly. For example, combining "'Control of competing vegetation'" and "Pest management and the elimination of chemicals" resulted in an Ontario score of eight for "'Pest and weed management and alternatives to chemicals." Similarly, combining "Development of 'naturalistic' management systems"' with " Silvicultural and harvesting methods and cost reduction'" resulted in a Nova Scotia score of seven for the latter heading. The elimination of the heading "Biotechnology" further reduced the number of topics in the Nova Scotia column.

The topics are by no means independent of one another. For example, the two top-rated subjects, "Environmental effects of forest management" and "Decision support for management, silviculture and land use" are closely linked with "Ecological knowledge for intensive forest management", and "Integrated forest management systems.',

A quick comparison of this year's listing of priorities with the lists in previous overviews might raise some concerns that priorities are changing more quickly than research programs can adjust. However, none of the research priorities in the list of 12 topics is new for 1991. Although the wording and the grouping were sometimes different, all of them were mentioned in the 1990 Research Priorities Overview, where a large majority of respondents identified most as priorities. The request for only the top five priorities from each jurisdiction has helped to focus attention on the major problems and research needs and made it possible to simplify the categorization of the topics.

\section{Priorities in Descending Order}

\section{Environmental Effects of Forest Management}

The top priority is for research on the environmental effects of forest management practices. There are two aspects to this issue. First, the effects of present and planned forestry practices on the total forest environment need to be better understood. For example, improved inventories and classification methods for gathering baseline data and subsequent long-term monitoring to detect changes are required. Second, a means of reducing deleterious effects must be devised. This may involve developing more benign timber-harvesting methods and integrating them better with regeneration of the next stand (see priority 3). An important step in realizing the above is the creation of a more environmentally conscious and bettertrained work force capable of doing specialized tasks. This is not often recognized as forest research, but is of great importance nevertheless.

\begin{tabular}{|c|c|c|c|c|c|c|c|c|c|c|c|c|c|}
\hline Research Topic & NF & NS & PE & NB & PQ & ON & MB & SK & $\mathbf{A B}$ & BC & YT & NT & SCORE \\
\hline $\begin{array}{l}\text { 1. Environmental effects of forest } \\
\text { management }\end{array}$ & 5 & 5 & & & & & 2 & & 5 & 5 & & & 22 \\
\hline $\begin{array}{l}\text { 2. Pest \& weed management \& } \\
\text { alternatives to chemicals }\end{array}$ & 4 & & 3 & 1 & 2 & 8 & & & 1 & & & & 19 \\
\hline $\begin{array}{l}\text { 3. Decision support for management, } \\
\text { silviculture \& land use }\end{array}$ & & & & 5 & 4 & 1 & 1 & 2 & 4 & & & & 17 \\
\hline $\begin{array}{l}\text { 4. Ecological knowledge for intensive } \\
\text { forest management }\end{array}$ & 2 & & 5 & & 5 & & & & & 3 & & & 15 \\
\hline $\begin{array}{l}\text { 5. Integrated resource management } \\
\text { systems }\end{array}$ & & & 4 & 3 & & & & 3 & & 4 & & & 14 \\
\hline 6. Site-productivity classification systems & & & 2 & & & & 5 & 5 & 2 & & & & 14 \\
\hline $\begin{array}{l}\text { 7. Growth \& yield data for managed \& } \\
\text { unmanaged stands }\end{array}$ & 3 & & & 4 & & & & 4 & & 1 & & & 12 \\
\hline $\begin{array}{l}\text { 8. Silvicultural \& harvesting methods \& } \\
\text { cost reduction }\end{array}$ & & 7 & & 2 & 3 & & & & & & & & 12 \\
\hline 9. Forest fire management \& control & & & 1 & & & 4 & 3 & & & & & & 8 \\
\hline 10. Tree improvement \& genetics & 1 & & & & & 2 & 4 & & & & & & 7 \\
\hline 11. Increasing forest productivity & & 2 & & & & & & & 3 & 2 & & & 7 \\
\hline $\begin{array}{l}\text { 12. Wood processing \& value-added } \\
\text { products }\end{array}$ & & & & & 1 & & & 1 & & & & & 2 \\
\hline
\end{tabular}




\section{Pest and Weed Management and Alternatives to Chemicals}

Better pest-management techniques, including the management of competing vegetation, is the second priority for forest research, with the desire for alternatives to chemical control methods being its most important aspect. The alternatives to chemicals have to be evaluated to determine all risks and benefits. Better means of assessing risk of pest outbreaks and their impact are also required.

\section{Decision Support for Management, Silviculture and Land Use}

The third priority is the development of improved support systems for making decisions on forest management, silvicultural treatments, and land-use options. This includes creating user-friendly expert systems to integrate better the data on all the factors that influence forest management and landuse choices and to evaluate the trade-offs that must be made in defining and choosing the optimum course of action. In addition, better information is required as input to decision support systems. This includes more data on the economics of various silvicultural operations to help develop selection criteria for appropriate treatments; better growth and yield data; and better information on the environmental consequences of various treatments. These matters are touched on under other headings.

\section{Ecological Knowledge for Intensive Forest Management}

The next priority, better fundamental knowledge of the dynamics of the forest ecosystems and their functioning, is closely related to priority 1 and the need for better evaluation of the impacts of various disturbances, such as harvesting, wind, pests, fire and global climatic change, on the forest ecosystem. This information is needed to be certain that management regimes and benefit flows are truly sustainable. To achieve this goal a fuller understanding of the functioning of forest ecosystems is necessary.

\section{Integrated Resource Management Systems}

Progress in developing workable integrated management systems for all the resources in the forest depends to a great degree on improving inventory and evaluation techniques for wildlife, water flow, and recreation values and obtaining more knowledge on forest succession, wildlife habitat and population responses to forest management strategies. This again underscores the importance of work described under priorities 1 and 4 .

\section{Site-Productivity Classification Systems}

Improving site-productivity classification systems and applying them more widely was assigned a high priority in the Prairie provinces, which accounts for its high overall rating. This is a good example of the differences that exist in forest-management needs and concerns across the country. Site-classification systems make it possible to extend research results more reliably so that management practices that are successful in one location can be applied with some confidence elsewhere.

\section{Growth and Yield Data for Managed and Unmanaged Stands}

Forest inventory information and growth and yield data are basic requirements for planning the timber aspects of forest management. Better data on the growth and yield of managed as well as unmanaged stands are a continuing need in many jurisdictions and have been given high priority in several.

\section{Silvicultural and Harvesting Methods and Cost Reduction}

Improving the efficiency and effectiveness of silvicultural and timber-harvesting techniques was given priority in several jurisdictions. One reason is the present stringent financial climate in governments and industry. Another factor is the need to tie harvesting and regeneration closer together and to devise systems that are environmentally sound and sustainable. Nova Scotia stressed the importance of devising methods that rely more on the natural dynamics of the forest and are less intrusive on the forest ecosystems. Examples cited include investigation of natural regeneration versus planting, effective manual weeding versus herbicide use, diversity versus monoculture. Such approaches are frequently more cost effective. The relationship with priorities 2 and 4 is obvious.

\section{Forest Fire Management and Control}

Forest fire control and management was given priority in three jurisdictions. Forest fires continue to have a deleterious effect on Canada's forests, with an annual average of about one million hectares burned and with periodic severe years when losses soar. The possible effect of global warming on fire hazard is also of concern. Computerized systems for integrating information and managing fire-fighting resources have greatly improved fire-control capability. Continued research to improve these methods and extend their application is needed.

\section{Tree Improvement and Genetics}

Tree improvement and genetics is equal in priority to increasing forest productivity and an important factor in attaining that objective. The potential for increasing timber yields through tree improvement is significant.

\section{Increasing Forest Productivity}

As pressures on the forest land base increase and more land is designated for recreation, wilderness preservation, and other uses, interest grows in increasing yields on land available for timber production. This involves improving silvicultural practices and is therefore closely related to priority 8 , aimed at improving the efficiency and effectiveness of silvicultural and timber-harvesting techniques. Better application of the more basic information that derives from several other research priorities is called for. More work is suggested in such areas as matching of species to site, careful selection of exotic species, quality control of planting stock and techniques for stand tending.

\section{Wood Processing and Value-Added Products}

Improving wood processing and developing value-added products is seen as a priority because of the importance of maintaining the competitive position of wood as a material and Canada as a trading nation. Reduction in energy demand is an important aspect, as is recycling and the need for products that will make the best use of present and future feed stocks. The potential of more valued-added products needs further examination. 


\section{Issues That May Affect Research Priorities}

A total of 13 issues were identified as having the potential to affect future research priorities. They are listed in Table 2 . Most were mentioned by only one or two respondents.

Public concern regarding forestry, the environment, and sustainable development was mentioned by four respondents and a glance at the research priorities discussion in this report reveals that it is already affecting research. The high priority given to the environmental effects of forest management and to the search for alternatives to chemical pesticides are examples.

Two of the issues identified for 1991 have not appeared in previous reports in this series, either as issues likely to affect future research or as research priorities. These subjects are closely allied and have to do with the export marketing of Canadian forest products, that is, "Globalization of trade and increased competition" and "International opinion about Canadian forestry practices." The effects on research could be quite profound. On the products side, new markets are possible, but stiff competition can be expected and existing markets may be restricted. These factors could generate requirements for new forest products and a demand for higher quality in existing products. On the forest management side, the call for research to increase understanding of the forest ecosystem and to devise, where necessary, different forest management techniques is likely to become more urgent.

A few topics in this listing of issues have appeared in previous lists of research priorities in this series of research priority overviews, for example, "Small-scale forestry on farms and for shelterbelts," "'Forestry on Indian lands,", and "'Properties of wood from managed stands.' Because they did not rate in the top five priorities in any jurisdiction, they are not in the 1991 priority listing. However, these and other concerns, many of which are of a local nature, must figure in selecting the final mix of research projects undertaken by any agency. The balance of the topics identified in the listing of issues appears to be self-explanatory and requires no further elaboration here.

\section{Adequacy of Funding}

As expected, the question about the adequacy of funding proved difficult. Several jurisdictions were either in the process of examining this issue or have yet to address it fully. The results summarized here may change as the present round of federal-provincial forestry agreement negotiations is completed. However, none of the 15 topics was considered to be adequately funded everywhere, and some topics were thought to be undersupported by all respondents who gave an opinion on funding. The environmental effects of forest management, the highest priority item, falls into this category.

Locally the situation differed somewhat and a few topics were considered adequately funded: for example, in Nova Scotia, naturalistic management systems, silvicultural and harvesting cost reduction, and increasing forest productivity; in New Brunswick, the development of decision support systems, growth and yield data, and pest management; in Quebec, wood processing, including pulp and paper research.

\section{Improving the Funding Situation}

The comments provided under this heading clearly demonstrate the importance of the federal-provincial forestry agreements in supporting forestry research in Canada. Many singled out these agreements as the most viable possibility for channeling more resources to urgent forest research. This approach is not without problems, however, and the stop-and-go nature of this funding and the difficulties it causes in planning and executing long-term forestry research was noted.

Table 2. Issues that may affect forest research priorities, 1991

\begin{tabular}{|c|c|c|c|c|c|c|c|c|c|c|c|c|c|}
\hline Issue Identified & NF & NS & PE & NB & PQ & ON & MB & SK & $\mathbf{A B}$ & $\mathbf{B C}$ & YK & NT & TOTAL \\
\hline $\begin{array}{l}\text { Public concern re forestry, environment, } \\
\text { sustainable development }\end{array}$ & 1 & & & & 1 & 1 & & 1 & & & & & 4 \\
\hline $\begin{array}{l}\text { International opinion re Canadian } \\
\text { forestry practices }\end{array}$ & 1 & & 1 & & & & & & & & & & 2 \\
\hline $\begin{array}{l}\text { Globalization of trade \& increased } \\
\text { competition }\end{array}$ & & & & & 1 & & & & & & & & 1 \\
\hline $\begin{array}{l}\text { Economics of viable secondary forest- } \\
\text { products industries }\end{array}$ & & & & & & & & 1 & & & & & 1 \\
\hline $\begin{array}{l}\text { Increasing needs for information at all } \\
\text { levels }\end{array}$ & & & & & 1 & & & & & & & & 1 \\
\hline $\begin{array}{l}\text { Shrinking forest land base for } \\
\text { sustained timber harvest }\end{array}$ & & 1 & & & & & & & & & & & $\begin{array}{l}1 \\
1\end{array}$ \\
\hline Forest modeling \& sustainable harvests & & 1 & & & & & & & & & & & \\
\hline $\begin{array}{l}\text { Information on socioeconomic } \\
\text { importance of forests }\end{array}$ & & & & & 1 & & & & & & & & 1 \\
\hline $\begin{array}{l}\text { Monitoring managed forest to ensure } \\
\text { predicted yields }\end{array}$ & & 1 & & & & & & & & & & & 1 \\
\hline Managing boreal mixed-wood resource & & & & & & & & 1 & & & & & 1 \\
\hline Forestry on Indian lands & & & & & & & & 1 & & & & & 1 \\
\hline $\begin{array}{l}\text { Small-scale forestry on farms \& for } \\
\text { shelterbelts }\end{array}$ & & & & & & & & 1 & & & & & 1 \\
\hline Properties of wood from managed stands & & 1 & & & & & & & & & & & 1 \\
\hline
\end{tabular}


Attention was also drawn to the great importance of assessing priorities and reallocating research funds from projects of lesser importance, when feasible.

The response indicated that more cooperative approaches are important in extending existing funds and in attracting new funds. For instance, joint projects involving industry, government agencies and universities could be established; neighboring provinces could work together more effectively on shared problems by establishing joint projects and utilizing agreement funds or other resources; special pools of research funds could be set up that draw on government, industry, and private sources and that would be jointly administered by a project-selection panel made up of representatives of industry, government, university, and non-government organizations; joint application by a group of researchers or their agencies to funding sources, such as the National Science and Engineering Council, could be made.

\section{Adequacy of Forest Research}

Several responses provided no comment on this issue because the necessary information was not available or had not yet been fully analyzed. Some noted that the issue is complex and that funding levels alone are unsatisfactory measures of the adequacy of research programs. The relevance of the research to needs and the quality of the science are considered the important criteria but are more difficult to apply.

In Newfoundland, research funds are limited by expenditures on other, more operational programs. In Nova Scotia, more funding is required, particularly for research on environmental questions and biotechnology. In Quebec, the bulk of the forest research is considered pertinent to needs, but more funding is required to make the research effort really reflect the importance of the resource and its use. Ontario emphasized that adequacy of funding is not the only important issue. More effort is required in coordinating efforts to tap into existing funding sources and in assessing priorities. Saskatchewan requires more research specifically tied to local conditions, suggesting that their reliance on imported research results has had a serious negative impact on applied research and trials. Alberta feels that all their top five priorities are inadequately supported, but that the program is well rounded, with a balance of basic, applied, environmental and forest management research. Levels of communication and cooperation are considered satisfactory in Alberta. In British Columbia, funding levels have increased since 1988, when the last assessment was made. A project has been initiated to review the status of research funding in that province.

\section{CIF/IFC Corporate Sustaining Members}
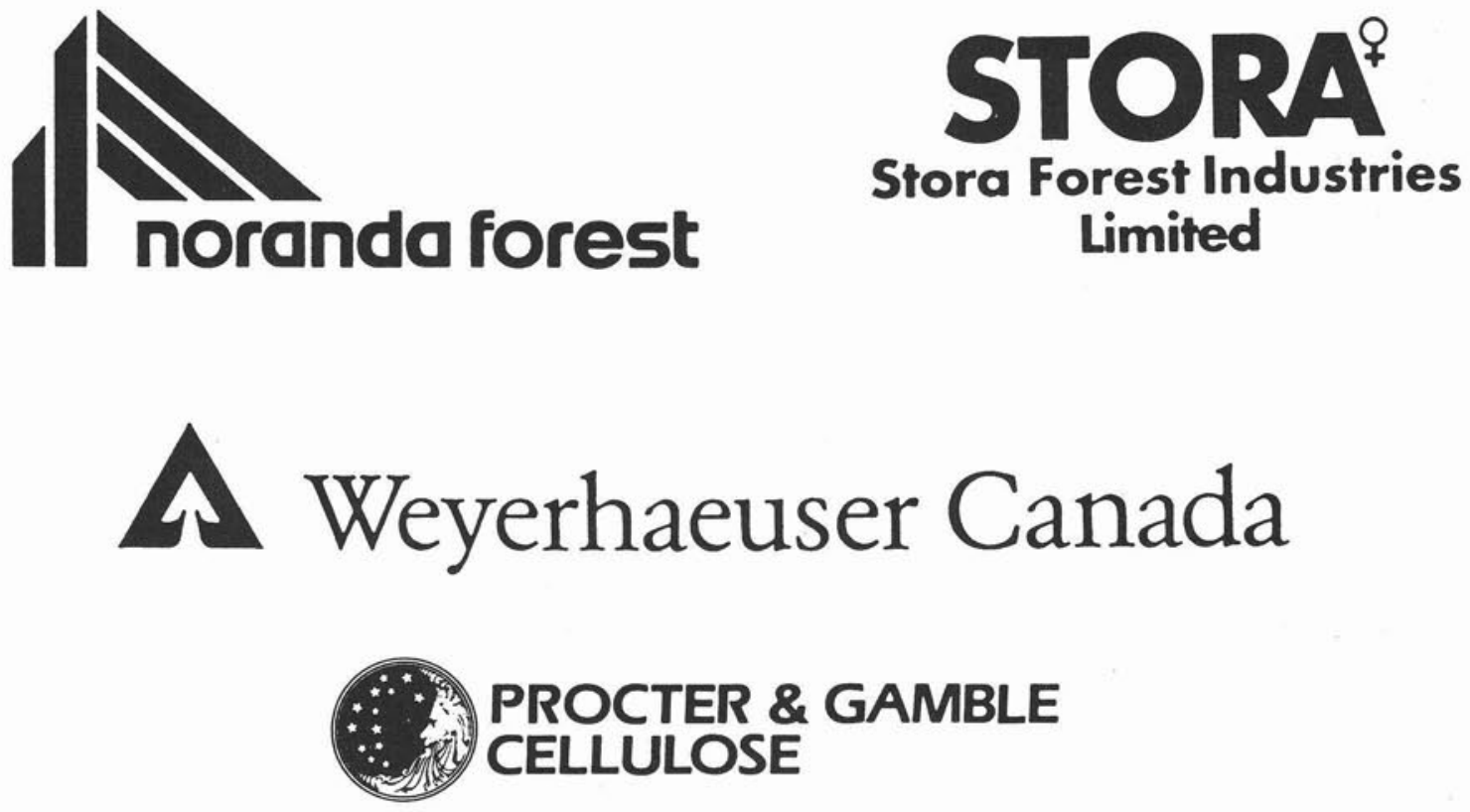